\title{
Studying the UO2 Electrochemistry In Situ Using SEM
}

\author{
Xiao-Ying Yu, Jennifer Yao, Sayandev Chatterjee, Jiyoung Son and Edgar Buck \\ Pacific Northwest National Laboratory, Richland, Washington, United States
}

Repositories for the disposal of radioactive waste depend on a multi-barrier system to segregate the waste from the biosphere. The multi-barrier system generally consists of the natural (geological) barrier by the repository host rock and its surroundings and an engineered barrier system (EBS). In situ and laboratory testing and modelling constitute an important aspect of research to ensure that an EBS will perform to its desired functions to contain spent uranium oxide $\left(\mathrm{UO}_{2}\right)$ fuel [1]. Of specific interest in the dissolution and oxidation of $\mathrm{UO}_{2}$ is the determination of its corrosion potential. Although such processes are described in the Mixed Potential Model (MPM) and Fuel Matrix Dissolution Model (FMDM), microscopic understanding of the electrochemical and diffusion processes is needed to validate advanced models such as MPM.

We use in situ liquid cell and microanalysis in scanning electron microscopy (SEM) to study $\mathrm{UO}_{2}$ chemistry following recent successes $[2,3]$. We invented a vacuum compatible microfluidic interface, System for Analysis at the Liquid Vacuum Interface (SALVI) to study liquids using vacuum surface tools including SEM [4, 5]. The electrochemical version of the E-cell [6] was redesigned to investigate the oxidation of $\mathrm{UO}_{2}$ in this work. This paper shows initial results of in operando study of spent fuel relevant systems using the SALVI E-cell. The radiological material was analyzed in the Quanta 250 FEG SEM housed in the Radiological Processing Laboratory (RPL) at the Pacific Northwest National Laboratory (PNNL). Non-radiological materials were analyzed to optimize imaging conditions. Optimized in situ SEM procedures were described earlier [7, 8]. Prior to performing microanalysis of $\mathrm{UO}_{2}$ in the microfluidic E-cell, the cyclic voltammagram of uranyl (VI) nitrate was acquired (Figure 1). The electrochemistry of U(VI) was run using a three-component electrochemical cell, with Pt-disc working electrode, $\mathrm{Pt}$ wire auxiliary electrode, and $\mathrm{Ag} / \mathrm{AgCl}$ as reference electrode.

Next, we performed electrochemistry experiments using a uranium containing electrolyte in the SALVI E-cell. An EHI 660 E (CH Instruments, Inc., Austin, TX) electrochemical workstation was used. The Ecell was mounted on the sample stage of the SEM and was tested. The three electrodes were connected to the electrochemical workstation via corresponding wires as shown in Figure 2. The electrochemistry of U (VI) was conducted using a three-electrode SALVI E-cell, with gold film $\left(\sim 1 \mathrm{~mm}^{2}\right)$ as working electrode, Pt wires as counter electrode and reference electrode, respectively. A series of in operando SEM experiments of $\mathrm{UO}_{2}$ will be performed to simulate the spent fuel conditions. New in situ SEM imaging results in studying nuclear materials will be presented [9]. 


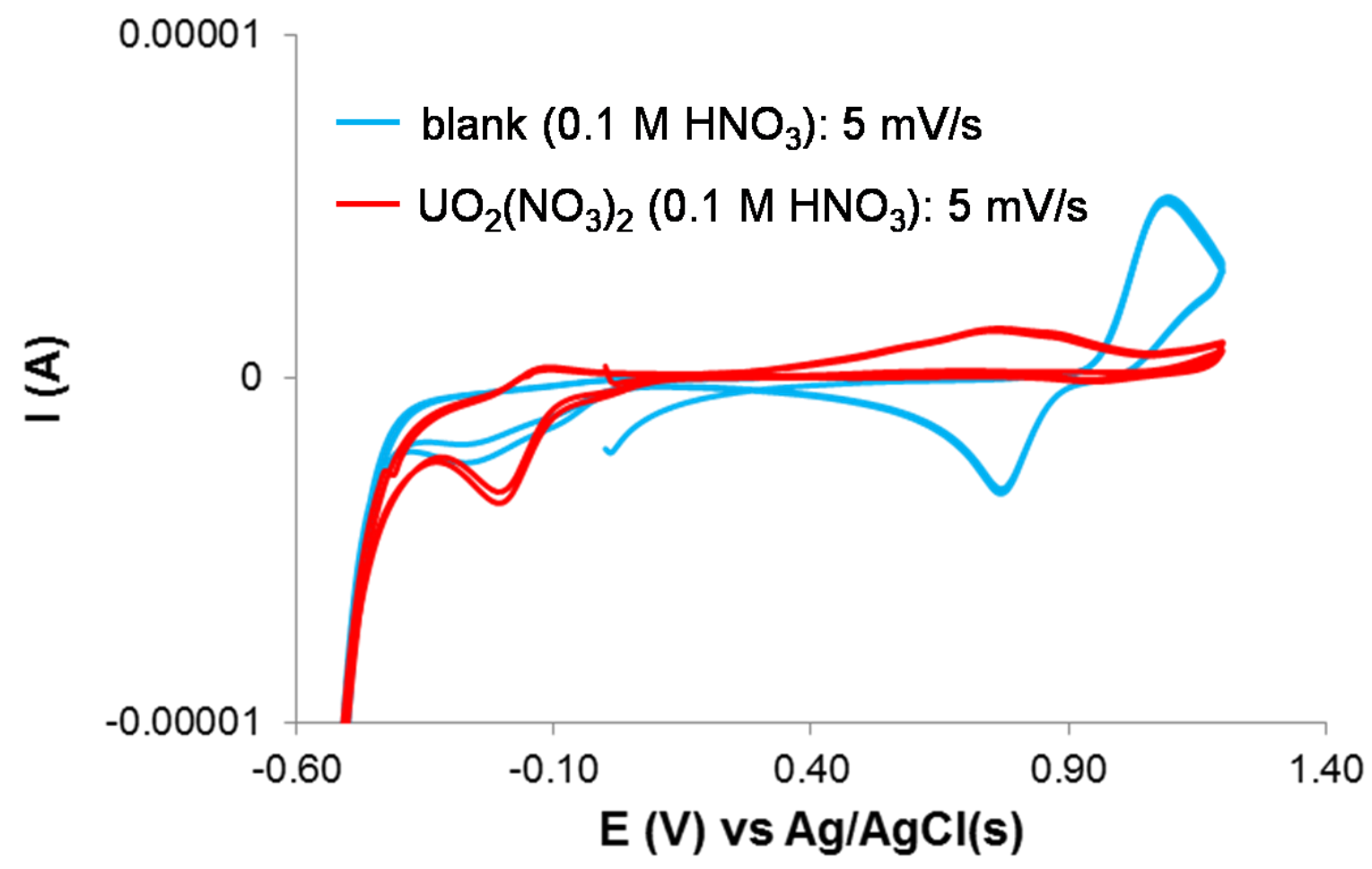

Figure 1. Cyclic voltammogram of $10 \mathrm{mM}$ uranyl (VI) nitrate in $0.1 \mathrm{M} \mathrm{HNO3.}$

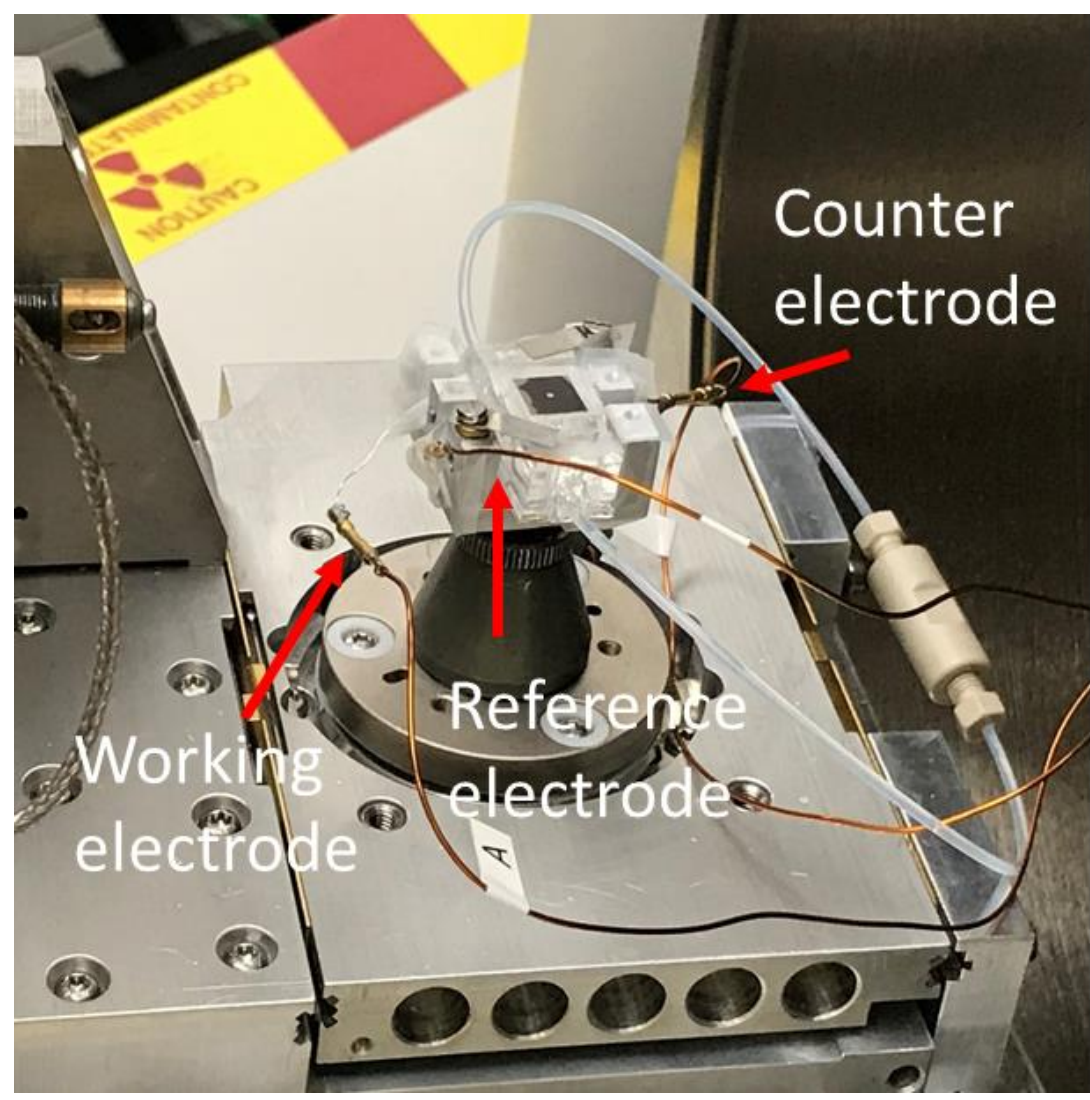

Figure 2. The SALVI E-cell with uranium containing electrolyte setup installed in the SEM stage. 


\section{References}

[1] JL Jerden et al., J. Nucl. Mater. 462, (2015), 135-146. doi: 10.1016/j.jnucmat.2015.03.036.

[2] EC Buck et al., RSC Advances, 8 (2018), 18227-18233.

[3] X-Y Yu, et al., Proceedings of the International High-Level Radioactive Waste Management (IHLRWM) Conference, Analysis of radioactive materials in liquid using in situ SEM and ToF-SIMS, April, 2019.

[4] L Yang et al., J. Vac. Sci. Technol. A 29 (2011), art. no., 061101. doi: 10.1116/1.3654147.

[5] L Yang et al., Lab Chip 11 (2011), 2481-4. doi: 10.1039/c01c00676a.

[6] J Yu et al., Chem. Comm. (2016), 52, 10952-5. doi: 10.1039/c6cc02893d.

[7] J Yao et al., J. Vis. Exp (2017), 127, e56058. doi: 10.3791/56058.

[8] X-Y Yu et al., Surface Interface Analysis (2019), 51 (13), 1325. doi: 10.1002/sia.6700

[9] We acknowledge support from the U.S. Department of Energy (DOE) Nuclear Energy (NE) Spent Fuel and Waste Science and Technology (SFWST) program. 